\title{
Quantitative plant proteomics using hydroponic isotope labeling of entire plants (HILEP)
}

Book or Report Section

Accepted Version

Bindschedler, L. V., Smith, C. J. and Cramer, R. K. (2011) Quantitative plant proteomics using hydroponic isotope labeling of entire plants (HILEP). In: Ivanov, A. R. and Lazarev, A. V. (eds.) Sample preparation in biological mass spectrometry. Springer, New York. ISBN 9789400707580 Available at https://centaur.reading.ac.uk/16311/

It is advisable to refer to the publisher's version if you intend to cite from the work. See Guidance on citing.

Published version at: http://www.springer.com/chemistry/analytical+chemistry/book/978-94-007-0758-0

Publisher: Springer

All outputs in CentAUR are protected by Intellectual Property Rights law, including copyright law. Copyright and IPR is retained by the creators or other copyright holders. Terms and conditions for use of this material are defined in the End User Agreement.

www.reading.ac.uk/centaur 
Central Archive at the University of Reading

Reading's research outputs online 


\section{CHAPTER XX}

\section{QUANTITATIVE PLANT PROTEOMICS USING}

\section{HYDROPONIC ISOTOPE LABELING OF ENTIRE}

\section{PLANTS (HILEP)}

Laurence V. Bindschedler, Celia J. Smith and Rainer Cramer

The BioCentre and Department of Chemistry, University of Reading, Reading, UK

*Address correspondence to:

Dr. Laurence V. Bindschedler, Department of Chemistry, University of Reading, Harborne Building, Whiteknights, PO Box 221, Reading, RG6 6AS, UK.

Tel.: +44-118-378-4564; FAX: +44-118-378-4551; e-mail: l.v.bindschedler@reading.ac.uk

or

Prof. Rainer Cramer, The BioCentre and Department of Chemistry, University of Reading, Harborne Building, Whiteknights, PO Box 221, Reading, RG6 6AS, UK.

Tel.: +44-118-378-4550; FAX: +44-118-378-4551; e-mail: r.k.cramer@reading.ac.uk

Keywords: HILEP, hydroponics, mass spectrometry, metabolic labeling, plant proteomics 


\title{
TABLE OF CONTENTS
}

\author{
XX.1 AbSTRACT
}

\section{XX.2 INTRODUCTION}

XX.2.1 Quantitative proteomics using non-MS methods

XX.2.2 Quantitative proteomics using MS-based methods

XX.2.2.1 Label-free methods

XX.2.2.2 Chemical labeling

XX.2.2.3 Metabolic labeling

XX.2.2.4 Hydroponic Isotope Labeling of Entire Plants (HILEP)

\section{XX.3 Procedure}

XX.3.1 Hydroponic cultivation and the generation of ${ }^{15} \mathrm{~N}$-labeled products

XX.3.2 Protein sample preparation

XX.3.3 Data analysis

\section{XX.4 SUMMARY}

\section{XX.5 ANNEX}

XX.5.1 Protocol 1. Hydroponic medium formulation for growing Arabidopsis thaliana plants

XX.5.2 Protocol 2. Growing Arabidopsis thaliana plants for HILEP

XX.5.3 Useful websites

\section{XX.6 REFERENCES}




\section{XX.1 AbSTRACT}

Hydroponic cultivation is a soil-free technique commonly used in agriculture where plants are grown in a highly controlled environment leading to high crop yields. Hydroponic Isotope Labeling of Entire Plants (HILEP) is the most cost-effective isotope labeling method for quantitative plant proteomics, enabling the metabolic labeling of whole and mature plants with a stable isotope such as ${ }^{15} \mathrm{~N}$. Employing inorganic ${ }^{15} \mathrm{~N}$ containing salts as the sole nitrogen source, healthy plants can be easily grown and labeled in hydroponic solutions. Close to $100 \%{ }^{15} \mathrm{~N}$-labeling of proteins can be achieved using HILEP. Moreover, hydroponic cultivation allows tight control of growth conditions. Plants grown in ${ }^{14} \mathrm{~N}$ - and ${ }^{15} \mathrm{~N}$-hydroponic media are typically pooled straight after harvest, eliminating any bias due to subsequent sample preparation and analysis. The pooled ${ }^{14} \mathrm{~N}-{ }^{15} \mathrm{~N}$-protein extracts can be fractionated in any convenient way and digested with trypsin (or any other enzyme of choice). Peptides can then be analyzed by techniques such as liquid chromatography electrospray ionization tandem mass spectrometry (LC-ESI-MS/MS). Following protein identification, the spectra of ${ }^{14} \mathrm{~N} /{ }^{15} \mathrm{~N}$-peptide pairs are typically compared and relative protein amounts are calculated from the ${ }^{14} \mathrm{~N} /{ }^{15} \mathrm{~N}$-ion signal ratios. An increasing number of bioinformatics tools are now available for determining these ratios in a convenient way. 


\section{XX.2 INTRODUCTION}

Despite the ever increasing demand for more accurate and sensitive analyses of whole proteomes, their quantitative analysis using mass spectrometry (MS) is still one of the major challenges in proteomics. The typically poor correlation between analyte concentration and signal intensity, which is due to variation in ionization efficiency in the presence of molecular competitors or contaminants, prevents straightforward quantitation using the recorded ion signal intensity. Unfortunately, the two widely used ionization techniques in proteomic MS, electrospray ionization (ESI) and matrix-assisted laser desorption/ionization (MALDI), are no exception to this limitation. However, most of the methods available to quantify entire proteomes are based on MS techniques involving the measurement of ion signal intensities.

Quantitative proteomic methods can be classified as either non-MS or MS-based methods as well as "labelfree” or "labeling”, of which the latter can be further sub-divided into the various types of labeling approaches such as chemical and metabolic labeling.

\section{XX.2.1 Quantitative proteomics using non-MS methods}

One of the most important non-MS approaches employs differential protein derivatization using fluorescent dyes such as CyDyes ${ }^{\mathrm{TM}}$. The protein samples to be compared are labeled using different dyes and are then pooled prior to protein separation by electrophoresis on the same gel, thus limiting quantitation errors that easily occur if samples are run on different gels (Marouga et al., 2005; Timms and Cramer, 2008; Unlu et al., 1997). This technique, called DIfference Gel Electrophoresis (DIGE), has the advantage of determining and then selectively quantifying the differentially expressed proteins (or protein isoforms), rather than identifying and quantifying the entire polypeptide content as it is the case in quantitative Multidimensional Protein Identification Technology (MudPIT) analyses. Although DIGE provides several advantages with respect to analyte separation, purification and enrichment as well as subsequent MS analysis time, it requires the use of expensive dyes and sophisticated image analysis software and is intrinsically limited by the disadvantages typical for gel electrophoretic separation of proteins. 
There are also other quantitative gel-based methods available such as ${ }^{35}$ S-labelling or quantitation of gel spots/bands by densitometry. However, DIGE has the inherent advantage of drastically reducing the technical bias of gel electrophoresis and is therefore often the method of choice for gel electrophoretic quantitation of proteins.

\section{XX.2.2 Quantitative proteomics using MS-based methods}

Unlike DIGE where the intensity of a protein spot is used for quantitation, the MS-based proteomic quantitation methods mostly employ the so-called "bottom-up" strategies by identifying and quantifying proteins at the peptide level using proteolytic digests and their MS (or MS/MS) analysis. Proteins are typically digested with a protease, usually trypsin, prior to detection and characterization of the resultant peptides by MS or tandem mass spectrometry (MS/MS). The amount of protein is determined by the ion intensities of the identified peptides or their MS/MS products. A protein is usually identified and quantified by more than one peptide, enabling statistical analysis and the discrimination between protein isoforms by selecting only the peptides specific to a single protein isoform (an isoform being defined by a gene locus). However, isoform-specific quantitation is often limited by the absence or low intensity of isoform-specific peptide ion signals as well as the sequence-determined possible limitation of detecting only one or a few isoform-specific peptides.

\section{XX.2.2.1 Label-free methods}

There are several quantitation methods available that directly exploit the recorded MS ion signal intensity without the use of any labeled internal standards or comparison between differentially labeled samples. These are called label-free methods. One such method, spectral counting (Ishihama et al., 2005), counts the number of recorded peptide spectra per protein and is based on the assumption that peptide ions from an abundant protein will be analyzed many more times than peptide ions from a protein that is less abundant. The exponentially modified Protein Abundance Index (emPAI) (Ishihama et al., 2005) is calculated from the number of spectral counts of each peptide identified in one protein. It takes into account the fact that 
generally more peptides are detected for larger proteins. The emPAI value is readily available when using the protein identification software Mascot (MatrixScience, London, UK).

Other label-free methods use the signal intensities of individual peptides rather than the spectral counts to compare the relative abundance of proteins between samples (Hughes et al., 2006; Palmblad et al., 2007b; Silva et al., 2005; Wang et al., 2006). However, this approach is only valid if the sets of samples to be compared are all relatively similar, as the presence of contaminants or other ion species will influence the intensity of an ion signal, due to ion suppression. For methods with LC separation, reproducibility of the chromatographic separation and software to align the LC peaks, as well as accurate mass measurement are all prerequisites for the success of this technique (Palmblad et al., 2007b; Silva et al., 2005).

\section{XX.2.2.2 Chemical labeling}

Other strategies that can be employed to circumvent the constraints of label-free quantitation include differential labeling of peptides with chemical tags, e.g. tags containing stable isotopes as reviewed in Ong and Mann (Ong and Mann, 2005). The advantage of isotope-labeled tags is that they are physically and chemically identical, with the exception of the labels' mass and/or isotope distribution. This means that it is possible to pool the samples after the labeling step and then determine the protein ratios by comparing ion intensities of the corresponding protein-derived light/heavy peptides or their fragment ions in the same mass spectrum. Thus, there is no requirement to align and match LC peaks from different runs, as is required for many of the label-free quantitation techniques. Chemical labeling with isotopes overcomes the problem of ion suppression encountered in label-free strategies and thus, reduces the need to run many MS technical replicates. The Isotope-Coded Affinity Tag (ICAT) approach, one of the first differential isotope labeling methods, uses two different mass tags $\left({ }^{12} \mathrm{C}_{9}\right.$ - and ${ }^{13} \mathrm{C}_{9}$-isotope labels), which specifically label cysteinecontaining peptides. Following their labeling, cysteine-containing peptides are affinity purified through the incorporated biotin moiety (Yi et al., 2005). Peptide pairs with 9 Da-mass difference are then detected by MS and their ion intensities are compared for relative quantitation. Similarly, Isotope Coded Protein Labeling (ICPL) (Schmidt et al., 2005) allows the differential isotope labeling of lysines and the differentially labeled peptides are analyzed by MS. Isobaric Tags for Relative and Absolute Quantitation (iTRAQ) also label lysines and have similar physico-chemical properties. However, iTRAQ tags have 
identical masses, thus relative abundance is not measured through the MS signal as with ICAT and ICPL but measured by MS/MS, determining the ion signal intensities of reporter ions of different mass that are generated by the MS/MS fragmentation process (Ross, 2006; Ross et al., 2004b). This method benefits from increased MS detection due to the contribution of all samples to the precursor ion signal. It was successfully applied to quantify the secreted proteome of Arabidopsis cells following the infection with the bacterial pathogen Pseudomonas syringae (Kaffarnik et al., 2009). Recently eight iTRAQ tags have become available allowing high multiplexing capacity (Ross, 2006; Ross et al., 2004b). Two-plex or sixplex Tandem Mass Tags or TMT are alternative isobaric tags that are similar to iTRAQ (Dayon et al., 2008). Many more stable isotope-labeling approaches are emerging such as RABA (Reductive Alkylation By Acetone, (Zhai et al., 2009)), ANIBAL (ANiline and Benzoic Acid Labeling of amino and carboxylic groups, (Boersema et al., 2009; Panchaud et al., 2008)) and stable isotope dimethyl labeling (Boersema et al., 2009). Many of these are quite attractive since they use low-cost reagents.

Rather than labeling peptides with chemical tags, isotope-labeling of peptides can also be performed by exchanging ${ }^{16} \mathrm{O}$ with ${ }^{18} \mathrm{O}$ during tryptic digestion when performed in heavy water $\left(\mathrm{H}_{2}{ }^{18} \mathrm{O}\right)$ (Yao et al., 2001). The 2 Da-mass shift is then detected via MS analysis.

Chemical labeling of peptides often modifies irreversibly specific amino acids. These modifications need to be considered when performing protein identification with search engines such as Mascot. Fortunately, most of the commonly used chemical labeling methods (e.g. ICAT, iTRAQ, ICPL, dimethylation, ${ }^{18} \mathrm{O}-$ exchange) are supported by Mascot.

However, despite of being a powerful approach for quantitative proteomics, chemical labeling does not overcome the variability between protein extracts (degradation, handling variability), as the labeling occurs after the extraction of proteins or even after tryptic digestion. In addition, costs of the labeling chemicals also need to be taken into consideration, as it can be a limiting factor for large-scale experiments.

\section{XX.2.2.3 Metabolic labeling}

Metabolic labeling, i.e. labeling proteins at the time of protein synthesis, by incorporation of stable isotopes such as ${ }^{15} \mathrm{~N}$ is an alternative strategy to chemical labeling. Samples are typically pooled at the harvesting 
stage prior to most of the sample handling including protein extraction. Labeling at this early stage avoids any technical bias that may occur later in the sample preparation workflow - for instance due to differences in protein extraction, fractionation or proteolysis. One of the main metabolic labeling strategies is Stable Isotope Labeling with Amino acids in Cell culture (SILAC) (Mann, 2006), where cells are grown in the presence of an amino acid that is labeled with ${ }^{13} \mathrm{C}$ and/or ${ }^{15} \mathrm{~N}$. Quantitation is then typically performed by comparing the MS signal intensities of samples grown in medium containing unlabeled ${ }^{12} \mathrm{C} /{ }^{14} \mathrm{~N}$-arginine or one of the labeled arginines, i.e. ${ }^{13} \mathrm{C} /{ }^{14} \mathrm{~N}$-, ${ }^{12} \mathrm{C} /{ }^{15} \mathrm{~N}$ - or ${ }^{13} \mathrm{C} /{ }^{15} \mathrm{~N}$-containing arginine. SILAC has been used to label proteins in Arabidopsis cell cultures, but because of the photosynthetic capacity of plants to fix carbon from atmospheric $\mathrm{CO}_{2}$, complete labeling is typically prevented (Gruhler et al., 2005). Partial labeling renders quantitation more difficult, especially as the level of labeling must first be established empirically and the uptake of the label is dependent on the exposure to light. Moreover, the price of labeled arginine makes SILAC an expensive technique for the quantitative analysis of whole and mature Arabidopsis plants. Alternative methods to SILAC have also been developed for metabolic labeling using ${ }^{15} \mathrm{~N}$ or ${ }^{13} \mathrm{C}$ (reviewed by Heck and Krijgsveld (Heck and Krijgsveld, 2004)), and have been successfully applied to E. coli (Ross et al., 2004a), mammalian cells (Conrads et al., 2001) and yeast (Kolkman et al., 2006). In these specific cases, the media contained mixed organic and inorganic nitrogen sources estimated to contain $98-99 \%{ }^{15} \mathrm{~N}$, which was supplied as ammonium and/or inorganic nitrate salt. This metabolic labeling approach was also successful for the quantitative analysis of whole organisms such as the nematode model Caenorhabditis elegans and the fruit fly Drosophila melanogaster that were fed on ${ }^{15} \mathrm{~N}$-labeled E. coli and yeast, respectively (Krijgsveld et al., 2003). For these organisms, which require a more complex feeding medium, it was still possible to have a near $100 \%$-labeling efficiency. Similarly, whole rats were labeled through a protein-free diet supplemented with ${ }^{15} \mathrm{~N}$ algal cells (Wu et al., 2004).

More recently, Arabidopsis cell cultures were labeled with ${ }^{15} \mathrm{~N}$ in a traditional Murashige and Skoog salt medium containing sucrose and inorganic ${ }^{15} \mathrm{~N}$-nitrate as the sole nitrogen source for quantifying proteins and nitrogen-containing metabolites (Benschop et al., 2007; Engelsberger et al., 2006). Similarly, young seedlings were grown in this medium in shaking liquid cultures (Huttlin et al., 2007; Nelson et al., 2007). However, as the Murashige and Skoog medium is relatively rich, the plants have to be grown in vitro and in sterile conditions which is less convenient, especially when the plants have to be grown to maturity. 
There is another metabolic labeling method that is inexpensive, robust and suitable for quantitative plant proteomics. Its basic principle has previously been employed for metabolic ${ }^{15} \mathrm{~N}$-labeling of whole hydroponically grown mature potato plants for the structural analysis of abundant tuber proteins such as patatin by nuclear magnetic resonance (NMR) spectroscopy (Ippel et al., 2004). This labeling method uses

${ }^{15} \mathrm{~N}$-salts in a hydroponic medium and is equally applicable to quantitative MS-based proteomic analysis of whole and mature plants, which has led to the introduction of Hydroponic Isotope Labeling of Entire Plants (HILEP) for relative quantitative proteomic analysis by mass spectrometry and is described and reviewed in this chapter.

\section{XX.2.2.4 Hydroponic Isotope Labeling of Entire Plants (HILEP)}

HILEP in combination with MS-based proteomic quantitation was developed and first employed in a proofof-principle study for quantifying the proteome of Arabidopsis leaves treated with hydrogen peroxide to mimic oxidative stress response (Palmblad et al, 2007, Bindschedler et al, 2008). Since hydroponic cultures are ideal for tightly controlling plant growth conditions, the use of HILEP provides optimal experimental conditions for the growth and labeling of whole and mature plants in an inexpensive and relatively simple medium. It enables the quantitative analysis at the molecular level of mature plants responding to environmental stimuli or diseases.

Hydroponics is plant cultivation in the absence of soil, using a nutrient solution instead. The term itself originates from the concatenation of two Greek words, meaning water-based labour. Most of the nutrients are provided as solutes in the hydroponic medium, which mainly consists of water and salts of potassium, phosphate, nitrate, ammonium, calcium chloride and magnesium sulfate. Plants can grow in the absence of organic nutrients as they can fix atmospheric carbon through photosynthesis. Hydroponic cultivation of plants is a very ancient technique established long before photosynthesis was discovered and understood. Indeed, it was probably the method of cultivation used in The Hanging Gardens of Babylon in 600 BC. It certainly had been used by the Egyptians around that time and by the Romans in ca. $200 \mathrm{BC}$. In the $11^{\text {th }}$ century, the Aztecs were using hydroponic cultivation on a regular basis, creating "floating gardens". The technology was brought back to Europe by the Spanish Conquistadores and since then has been scientifically investigated. Further development during and after World War II has led to the use of 
hydroponics as a modern cultivation technique for intensive and high yield farming

(http://www.hydroponicsonline.com/lessons/History/lesson2-1history.htm; (Jones, 1982; Jones, 1997).

Recently, the near $100 \%$ complete metabolic labeling of entire and mature plants using hydroponics was

first described in the production of $3.6 \mathrm{~kg}$ of labeled potato tubers for the 3D structural analysis of abundant proteins such as patatin and Kunitz-type protein inhibitors using NMR spectroscopy (Ippel et al., 2004).

As mentioned earlier plants are photosynthetic organisms and thus are able to fix carbon from atmospheric $\mathrm{CO}_{2}$. Therefore, ${ }^{13} \mathrm{C}$-labeling would be inappropriate if near $100 \%$ metabolic labeling is required. Stable isotope labeling with ${ }^{15} \mathrm{~N}$ is more suitable, especially as ${ }^{15} \mathrm{~N}$-salts are cheaper. Near $100 \%$-labeling of proteins with ${ }^{15} \mathrm{~N}$ gives the advantage of having two distinct isotopic envelopes for the ${ }^{14} \mathrm{~N}$ - and ${ }^{15} \mathrm{~N}$-labeled peptides, thus avoiding the requirement to use complex mathematical tools for estimating the ratio between the light (unlabeled) and heavy (labeled) peptides or to use techniques such as Subtle Modification of Isotope Ratio Proteomics or SMIRP (Whitelegge et al., 2004). The latest advances in quantitative plant proteomics including stable isotope labeling have recently been reviewed (Oeljeklaus et al., 2009; Thelen and Peck, 2007). It appears that the use of metabolic ${ }^{15} \mathrm{~N}$-labeling is becoming the method of choice for in vivo labeling of plant proteins for quantitative proteomics using MS (Bindschedler et al., 2008; Hebeler et al., 2008; Huttlin et al., 2007; Nelson et al., 2007; Palmblad et al., 2007a; Palmblad et al., 2008). Most of these techniques resemble HILEP or are variations of HILEP such as Stable Isotope Labeling for In Planta quantitative proteomics (SILIP), which was employed to label tomato plants grown in a hydroponic medium containing inorganic soil substrates such as river sand (Schaff et al., 2008). It was also shown that HILEP can be employed for multiplex quantitation of up to four different samples (Palmblad et al., 2008). 


\section{XX.3. Procedure}

\section{XX.3. 1 Hydroponic cultivation and the generation of ${ }^{15} \mathrm{~N}$-labelled products}

Optimal conditions for the metabolic ${ }^{15} \mathrm{~N}$-labeling of Arabidopsis plants using hydroponic cultivation were established in previous studies, (Bindschedler et al., 2008; Palmblad et al., 2007a; Palmblad et al., 2008) based on a modified Hoagland's hydroponic medium (Hoagland, 1920), which was adapted using other published protocols (Huttlin et al., 2007; Huttner and Bar-Zvi, 2003; Noren et al., 2004). Protocol 1 (see Annex) details the hydroponic medium formulation as used in (Bindschedler et al., 2008). Protocol 2 (see Annex) describes the hydroponic cultivation of Arabidopsis thaliana from seed to mature plant. The general workflow of the experimental procedure is shown in Figure 1A.

To facilitate the identification of ${ }^{15} \mathrm{~N}$-labeled peptides, it is preferable to label plants with the highest possible percentage of ${ }^{15} \mathrm{~N}$ in the nitrogen-containing salts, as the maximum peak intensity of the isotopic envelope of peptides from plants grown in media with salts containing $90 \%{ }^{15} \mathrm{~N}$ is already shifted by 1 Da compared to plants grown in a $100 \%{ }^{15} \mathrm{~N}$ medium (Zhang et al., 2009). Salts containing $98-99 \%{ }^{15} \mathrm{~N}$ are widely commercially available at a modest cost compared to labeled amino acids as used in SILAC. As a typical example, Figure 1B shows the MS spectrum of a ${ }^{14} \mathrm{~N} /{ }^{15} \mathrm{~N}$-peptide pair and the MS/MS spectra of each peptide species. ${ }^{15} \mathrm{~N}$-salts were provided as $98+\%$ ammonium and potassium nitrate. To produce $1 \mathrm{~g}$ of hydroponically grown ${ }^{15} \mathrm{~N}$-labeled leaves costs about $£ 5$ using the protocols described in this chapter. Arabidopsis plants exhibit a healthy appearance when grown under these conditions, and no phenotypic differences can be detected between hydroponically grown ${ }^{14} \mathrm{~N}$ and ${ }^{15} \mathrm{~N}$ plants (see Figure 2).

\section{XX.3.2. Protein sample preparation}

After harvesting the plant material an equal amount of fresh weight of the ${ }^{14} \mathrm{~N}$-sample and the ${ }^{15} \mathrm{~N}$-sample are typically pooled prior to further processing. This way, both samples are processed together, avoiding variability in sample handling, loss and degradation. The preparation workflow may then include any type of protein extraction, cell/protein fractionation (e.g. protein precipitation, intercellular washing fluid (IWF) protein extraction, membrane protein enrichment), enzymatic treatment, polypeptide 
purification/enrichment, analytical preparation and other sample processing steps (see protocols and methods in other chapters).

\section{XX.3.3 Data analysis}

Several bioinformatics tools have been developed for the relative quantitation of proteomes (for review see (Mueller et al., 2008) and find a list of free software at http://www.ms-utils.org/). Unlike quantitation with some chemical tags or with ${ }^{18} \mathrm{O} /{ }^{16} \mathrm{O}$-labeling during proteolysis, the mass difference between light $\left({ }^{14} \mathrm{~N}\right)$ and heavy $\left({ }^{15} \mathrm{~N}\right)$ peptides is dependent on the amino acid composition of the peptide. Even for peptides labeled with heavy/light arginine in SILAC experiments, the mass difference is usually fixed, since most proteolytic steps in proteomic analyses are performed with trypsin which cuts after arginine and lysine. Thus, early bioinformatics tools for MS-based proteomic quantitation using methods such as SILAC needed to be modified for peptide quantitation based on global ${ }^{15} \mathrm{~N}$-labeling (Palmblad et al., 2007a).

In references (Bindschedler et al., 2008; Palmblad et al., 2007a), an automated data analysis pipeline is described for the routine application of HILEP in an integrated analytical workflow using the freely available Trans-Proteomic Pipeline (TPP) software suite, which can be down-loaded from http://tools.proteomecenter.org/software.php (Keller et al., 2005). The main steps in this data analysis workflow were as follows:

1. LC-MS/MS raw data files were converted into mzXML files.

2. Peak list files compatible with the Mascot protein search engine and with TPP (e.g. mgf files) were generated.

3. ${ }^{14} \mathrm{~N}$ - and ${ }^{15} \mathrm{~N}$-proteins were identified separately with Mascot, generating dat result files (http://www.matrixscience.com), which were converted to ${ }^{14} \mathrm{~N}$-pepXML or ${ }^{15} \mathrm{~N}$-pepXML files in the TPP suite.

4. In the TPP suite, the ${ }^{14} \mathrm{~N}$-pepXML files and their corresponding MS/MS raw datafiles (mzXML files) were then merged using the xINTERACT program. The whole process was repeated for the ${ }^{15} \mathrm{~N}$-pepXML files and their corresponding MS/MS raw data files (mzXML files). 
5. Peptide ratios were calculated using the XPRESS algorithm (Han et al., 2001). PeptideProphet (Keller et al., 2002) was then used to show peptide ratios and to allow statistical analysis of protein abundance.

6. Protein identifications and relative protein abundances were then displayed in a single protXML file using the ProteinProphet viewer (Nesvizhskii et al., 2003) in TPP.

7. Results were extracted into a spreadsheet for further statistical analysis.

In this specific case, at least 3 peptides were used to estimate the relative protein amount. Also, each peptide had to be unique to a single protein isoform, to avoid the possibility of calculating mixed ratios if a peptide is shared by more than a single protein isoform. Algorithms had been developed for each of these steps to facilitate batch processing and to automate the procedure for high-throughput analysis. Details can be found in (Bindschedler et al., 2008; Palmblad et al., 2007a).

The above data analysis workflow was validated by manual analysis. The $m / z$ value, the charge and the chromatographic elution time of the peptides of interest were retrieved from the Mascot search results, thus allowing the extraction of the corresponding ion chromatographic peak. The ${ }^{14} \mathrm{~N}$ - and ${ }^{15} \mathrm{~N}$-isotope envelopes were manually examined and the total areas of both the ${ }^{14} \mathrm{~N}$ - and the corresponding ${ }^{15} \mathrm{~N}$-peptide were calculated to estimate the abundance ratio. The mass difference between the most abundant peaks in the ${ }^{14} \mathrm{~N}$ - and ${ }^{15} \mathrm{~N}$-envelope was correlated to the number of nitrogen atoms deduced from the amino acid sequence. Examples of peptides present in different ratios (approximately 1:1, 1:2 and 5:1, respectively) that were manually quantified are shown in Figure 3.

However, since metabolic ${ }^{15} \mathrm{~N}$-labeling is becoming popular for quantitative proteomics, particularly in plant proteomics, there are now alternatives to the above workflow. Nonetheless, the number of ready-to-use tools for the quantitative analysis of ${ }^{15} \mathrm{~N}$-labeled proteins is still limited. The MSQuant tool and the XPRESS algorithm in TPP were originally developed for SILAC and ICAT, respectively, and need some supplementary programs to be applicable to global ${ }^{15} \mathrm{~N}$-labeling. The use of MSQuant is further restricted as it was only designed to be compatible with three MS instruments and for the use of Mascot ((Mueller et al., 2008), http://www.ms-utils.org). The RelEx quantitation software seems to be suitable for any type of labeling but is restricted to the analysis of Finnigan Xcalibur datafiles (MacCoss et al., 2003). On the other 
hand the TPP pipeline supports most types of MS/MS data as well as several search engines, such as X!Tandem, Phenyx, MASCOT and SEQUEST.

Another addition to the software tools for quantitative proteomic analysis of globally ${ }^{15} \mathrm{~N}$-labeled peptides is the quantitation toolbox within Mascot Distiller (MatrixScience). This toolbox is an integrated system that does not require programming skills, as all the processes from generating peak lists to peptide quantitation and statistics are integrated in the same software package for straightforward end-user applications. 


\section{XX.4 SUMMARY}

HILEP is a cost-effective and robust method for accurate quantitative analysis of proteomes of whole and mature plants. It produces healthy-looking plants in a controlled environment, requiring little "gardening" time. HILEP is readily applicable to various plant systems and bioanalytical applications. 


\section{XX.5 ANNEX}

\section{XX.5.1 Protocol 1. Hydroponic medium formulation for growing Arabidopsis thaliana plants}

Hydroponic medium formulation (as described in (Bindschedler et al., 2008)).

1. Prepare the following stock solutions and store them at $4^{\circ} \mathrm{C}$ :

$\begin{array}{llll}\text { Stock solutions } & \text { MW } & \text { amount in } \mathbf{5 0 ~ m L} \\ 1 \mathrm{M} & \mathrm{KNO}_{3} & 101.0 / 102.0^{*} & 5.05 / 5.1^{*} \mathrm{~g} \\ 1 \mathrm{M} & \mathrm{CaCl}_{2} & 147.0 & 7.35 \mathrm{~g} \\ 1 \mathrm{M} & \mathrm{MgSO}_{4} \cdot 7 \mathrm{H}_{2} \mathrm{O} & 246.5 & 12.3 \mathrm{~g} \\ 1 \mathrm{M} & \mathrm{KH}_{2} \mathrm{PO}_{4} \cdot & 136.1 & 6.8 \mathrm{~g} \\ 1 \mathrm{M} & \mathrm{NH}_{4} \mathrm{NO}_{3} & 236.0 / 238.0 * & 11.8 / 11.9^{*} \mathrm{~g} \\ 70 \mathrm{mM} & \text { Fe-EDTA } & 367.1 & 0.13 \mathrm{~g} \\ \text { *for } & & \\ & & & \end{array}$

2. Prepare the micronutrient stock solution and store at $-20^{\circ} \mathrm{C}$ :

$\begin{array}{llll} & \text { Micronutrients } & \text { MW } & \text { amount in } \mathbf{1 0 0} \mathbf{~ m L} \\ 50 \mathrm{mM} & \mathrm{H}_{3} \mathrm{BO}_{3} & 61.8 & 0.31 \mathrm{~g} \\ 10 \mathrm{mM} & \mathrm{MnSO}_{4} \cdot \mathrm{H}_{2} \mathrm{O} & 169.0 & 0.17 \mathrm{~g} \\ 1.5 \mathrm{mM} & \mathrm{ZnSO}_{4} \cdot 7 \mathrm{H}_{2} \mathrm{O} & 287.5 & 0.043 \mathrm{~g} \\ 1 \mathrm{mM} & \mathrm{CuSO}_{4} \cdot 5 \mathrm{H}_{2} \mathrm{O} & 249.7 & 0.025 \mathrm{~g} \\ 0.58 \mathrm{mM} & \mathrm{Na}_{2} \mathrm{MoO}_{4} & 241.9 & 0.014 \mathrm{~g}\end{array}$

3. To prepare $1 \mathrm{~L}$ of full-strength hydroponic solution, mix

Stock solutions of

$\mathrm{KNO}_{3}$

$\mathrm{CaCl}_{2}$

$\mathrm{MgSO}_{4}$

\section{Volume (mL)}

2.5

1

0.75 


$\begin{array}{lc}\mathrm{KH}_{2} \mathrm{PO}_{4} & 0.5 \\ \mathrm{NH}_{4} \mathrm{NO}_{3} & 0.5 \\ \text { Fe-EDTA solution } & 1 \\ \text { Micronutrients solution } & 1 \\ \text { and make up to } 1 \mathrm{~L} \text { in distilled water (store at } 4^{\circ} \mathrm{C} \text { or sterilize if kept at room temperature). }\end{array}$

Sterile, half-strength solution containing $0.7 \%$ agar is used to germinate seeds (for 10-15 days). Seedlings are then transplanted into full-strength solution. 


\section{XX.5.2 Protocol 2. Growing Arabidopsis thaliana plants for HILEP}

Growing Arabidopsis plants in ${ }^{14} \mathrm{~N}$ or ${ }^{15} \mathrm{~N}$ hydroponic medium (Bindschedler et al., 2008).

1. Seed sterilization as described by Noren et al. (Noren et al., 2004).

Place the required amount of seeds in a microcentrifuge tube. Wash these successively in:
a. $70 \%$ Ethanol $5 \mathrm{~min}$
b. $0.5 \%$ SDS $\quad 15 \mathrm{~min}$

Rinse three times with sterile distilled water.

At this stage the seeds can be stored in sterile water in the fridge for up to one week.

2. Autoclave a box of $200 \mu \mathrm{L}$-pipette tips (ensuring that the box has a transparent lid as it will be used to create a mini-greenhouse).

3. Make up a $0.7 \%$ agar solution containing half-strength hydroponic solution and autoclave it to ensure sterility.

4. Aseptically fill the sterile pipette tips with the molten agar solution (at $\sim 50-60^{\circ} \mathrm{C}$ ). Initially, add only a few 10-20 $\mu \mathrm{L}$-droplets and let them solidify, sealing the tips before filling them completely. Make sure there is a convex dome of agar as the gel will shrink when drying. Cover with the transparent lid and let the agar set.

5. Place one seed in the centre of each pipette tip cone using a 100-200 $\mu \mathrm{L}$-pipettor under aseptic conditions. Close the pipette tip box and seal with parafilm ${ }^{\mathrm{TM}}$, vernalise the seeds by placing the mini-greenhouse at $4^{\circ} \mathrm{C}$ (fridge) for at least $48 \mathrm{~h}$. Alternatively, the vernalisation can take place after the seeds are sterilized and stored in water (step 1) prior to adding the seeds to the agar.

6. Place the mini-greenhouse in a growth cabinet under a short day light regime, $10 \mathrm{~h}$ of light at $23^{\circ} \mathrm{C}$ and $14 \mathrm{~h}$ darkness at $20^{\circ} \mathrm{C}$ with $60 \%$ humidity.

7. After 10-15 days, before the roots reach the lower part and grow out of the tip, remove the parafilm $^{\mathrm{TM}}$ seal. Cut the end of the tip at one third of its length and replace the lid without sealing. At this stage the growth conditions are non-sterile but keep the system as clean as possible.

8. To grow the plants hydroponically, paint 1 L-lunch boxes with black acrylic paint on the outside to avoid algae growth. An example of an ideal box size is $21 \mathrm{~cm} \times 14 \mathrm{~cm} \times 5 \mathrm{~cm}$. The lids should have a rubber seal and four clamps for tight closure. Drill twelve holes (4x3) in the lid to hold 12 
plantlets in each box. Wash the boxes thoroughly and sterilize the inner surface with ethanol or by exposure to UV light. Once prepared, fill the boxes with one liter of full-strength hydroponic solution.

9. After 12-15 days (4 leaves stage), transfer the tips that contain a healthy seedling into the holes of the perforated box lid. Plants are then placed back in the growth cabinet, and left to grow until they are at the age required. Top up the hydroponic solution whenever necessary. Plants should have large healthy looking leaves with no necrosis or chlorosis. Roots should have formed a network in the hydroponic solution.

10. (Optional) Drill an additional hole in the lid to hold tubing for oxygenating the solution via an aquarium pump. A pump for a $45 \mathrm{~L}$-aquarium can aerate four boxes. If an aquarium pump is used, the growth medium should be changed weekly as contaminants may grow quicker under these conditions. This was observed even when a $0.22 \mu \mathrm{m}$-filter was added between the pump and the solution.

\section{XX.5.3 Useful Websites}

http://www.ionsource.com/functional_reviews/CompassXport/CompassXport.htm

http://tools.proteomecenter.org

http://www.matrixscience.com

http://www.ms-utils.org (http://www.ms-utils.org/pepXML2Excel.html) 


\section{XX.6 REFERENCES}

Benschop, J.J., Mohammed, S., O'Flaherty, M., Heck, A.J., Slijper, M., and Menke, F.L. (2007). Quantitative phospho-proteomics of early elicitor signalling in Arabidopsis. Mol Cell Proteomics., 6, 11981214

Bindschedler, L.V., Palmblad, M., and Cramer, R. (2008). Hydroponic isotope labelling of entire plants (HILEP) for quantitative plant proteomics; an oxidative stress case study. Phytochemistry 69, 1962-1972. Boersema, P.J., Raijmakers, R., Lemeer, S., Mohammed, S., and Heck, A.J. (2009). Multiplex peptide stable isotope dimethyl labeling for quantitative proteomics. Nat Protoc 4, 484-494.

Conrads, T.P., Alving, K., Veenstra, T.D., Belov, M.E., Anderson, G.A., Anderson, D.J., Lipton, M.S., Pasa-Tolic, L., Udseth, H.R., Chrisler, W.B., et al. (2001). Quantitative analysis of bacterial and mammalian proteomes using a combination of cysteine affinity tags and 15N-metabolic labeling. Anal Chem 73, 21322139.

Dayon, L., Hainard, A., Licker, V., Turck, N., Kuhn, K., Hochstrasser, D.F., Burkhard, P.R., and Sanchez, J.C. (2008). Relative quantification of proteins in human cerebrospinal fluids by MS/MS using 6-plex isobaric tags. Anal Chem 80, 2921-2931.

Engelsberger, W.R., Erban, A., Kopka, J., and Schulze, W.X. (2006). Metabolic labeling of plant cell cultures with K15NO3 as a tool for quantitative analysis of proteins and metabolites. Plant Methods 2, 14. Gruhler, A., Schulze, W.X., Matthiesen, R., Mann, M., and Jensen, O.N. (2005). Stable isotope labeling of Arabidopsis thaliana cells and quantitative proteomics by mass spectrometry. Mol Cell Proteomics 4, 16971709.

Han, D.K., Eng, J., Zhou, H., and Aebersold, R. (2001). Quantitative profiling of differentiation-induced microsomal proteins using isotope-coded affinity tags and mass spectrometry. Nat Biotechnol 19, 946-951.

Hebeler, R., Oeljeklaus, S., Reidegeld, K.A., Eisenacher, M., Stephan, C., Sitek, B., Stuhler, K., Meyer, H.E., Sturre, M.J., Dijkwel, P.P., et al. (2008). Study of early leaf senescence in Arabidopsis thaliana by quantitative proteomics using reciprocal 14N/15N labeling and difference gel electrophoresis. Mol Cell Proteomics 7, 108-120.

Heck, A.J., and Krijgsveld, J. (2004). Mass spectrometry-based quantitative proteomics. Expert Rev Proteomics 1, 317-326.

Hoagland, D. (1920). Optimum nutrient solutions for plants. Science 52, 562-564.

Hughes, M.A., Silva, J.C., Geromanos, S.J., and Townsend, C.A. (2006). Quantitative proteomic analysis of drug-induced changes in mycobacteria. J Proteome Res 5, 54-63.

Huttlin, E.L., Hegeman, A.D., Harms, A.C., and Sussman, M.R. (2007). Comparison of full versus partial metabolic labeling for quantitative proteomics analysis in Arabidopsis thaliana. Mol Cell Proteomics 6, 860881.

Huttner, D., and Bar-Zvi, D. (2003). An improved, simple, hydroponic method for growing Arabidopsis thaliana. Plant Molecular Biology Reporter 21, 59-63.

Ippel, J.H., Pouvreau, L., Kroef, T., Gruppen, H., Versteeg, G., van den Putten, P., Struik, P.C., and van Mierlo, C.P. (2004). In vivo uniform (15)N-isotope labelling of plants: using the greenhouse for structural proteomics. Proteomics 4, 226-234.

Ishihama, Y., Oda, Y., Tabata, T., Sato, T., Nagasu, T., Rappsilber, J., and Mann, M. (2005). Exponentially modified protein abundance index (emPAI) for estimation of absolute protein amount in proteomics by the number of sequenced peptides per protein. Mol Cell Proteomics 4, 1265-1272.

Jones, J.B. (1982). Hydroponics - Its History and Use in Plant Nutrition Studies. Journal of Plant Nutrition 5, 1003-1030.

Jones, J.B. (1997). Hydroponics. A Practical Guide for the Soilless Grower (Taylor \& Francis Ltd). Kaffarnik, F.A., Jones, A.M., Rathjen, J.P., and Peck, S.C. (2009). Effector proteins of the bacterial pathogen Pseudomonas syringae alter the extracellular proteome of the host plant, Arabidopsis thaliana. Mol Cell Proteomics 8, 145-156.

Keller, A., Eng, J., Zhang, N., Li, X.J., and Aebersold, R. (2005). A uniform proteomics MS/MS analysis platform utilizing open XML file formats. Mol Syst Biol 1, 20050017.

Keller, A., Nesvizhskii, A.I., Kolker, E., and Aebersold, R. (2002). Empirical statistical model to estimate the accuracy of peptide identifications made by MS/MS and database search. Anal Chem 74, 5383-5392. Kolkman, A., Daran-Lapujade, P., Fullaondo, A., Olsthoorn, M.M., Pronk, J.T., Slijper, M., and Heck, A.J. (2006). Proteome analysis of yeast response to various nutrient limitations. Mol Syst Biol 2, 20060026. 
Krijgsveld, J., Ketting, R.F., Mahmoudi, T., Johansen, J., Artal-Sanz, M., Verrijzer, C.P., Plasterk, R.H., and Heck, A.J. (2003). Metabolic labeling of C. elegans and D. melanogaster for quantitative proteomics. Nat Biotechnol 21, 927-931.

MacCoss, M.J., Wu, C.C., Liu, H., Sadygov, R., and Yates, J.R., 3rd (2003). A correlation algorithm for the automated quantitative analysis of shotgun proteomics data. Analytical chemistry 75, 6912-6921.

Mann, M. (2006). Functional and quantitative proteomics using SILAC. Nat Rev Mol Cell Biol 7, 952-958. Marouga, R., David, S., and Hawkins, E. (2005). The development of the DIGE system: 2D fluorescence difference gel analysis technology. Anal Bioanal Chem 382, 669-678.

Mueller, L.N., Brusniak, M.Y., Mani, D.R., and Aebersold, R. (2008). An assessment of software solutions for the analysis of mass spectrometry based quantitative proteomics data. J Proteome Res 7, 51-61.

Nelson, C.J., Huttlin, E.L., Hegeman, A.D., Harms, A.C., and Sussman, M.R. (2007). Implications of 15Nmetabolic labeling for automated peptide identification in Arabidopsis thaliana. Proteomics 7, 1279-1292.

Nesvizhskii, A.I., Keller, A., Kolker, E., and Aebersold, R. (2003). A statistical model for identifying proteins by tandem mass spectrometry. Anal Chem 75, 4646-4658.

Noren, H., Svensson, P., and Andersson, B. (2004). A convenient and versatile hydroponic cultivation system for Arabidopsis thaliana. Physiologia Plantarum 121, 343-348.

Oeljeklaus, S., Meyer, H.E., and Warscheid, B. (2009). Advancements in plant proteomics using quantitative mass spectrometry. J Proteomics 72, 545-554.

Ong, S.E., and Mann, M. (2005). Mass spectrometry-based proteomics turns quantitative. Nat Chem Biol 1, 252-262.

Palmblad, M., Bindschedler, L.V., and Cramer, R. (2007a). Quantitative proteomics using uniform (15)Nlabeling, MASCOT, and the trans-proteomic pipeline. Proteomics 7, 3462-3469.

Palmblad, M., Mills, D.J., and Bindschedler, L.V. (2008). Heat-shock response in Arabidopsis thaliana explored by multiplexed quantitative proteomics using differential metabolic labeling. J Proteome Res 7 , 780-785.

Palmblad, M., Mills, D.J., Bindschedler, L.V., and Cramer, R. (2007b). Chromatographic alignment of LCMS and LC-MS/MS datasets by genetic algorithm feature extraction. J Am Soc Mass Spectrom 18, 18351843.

Panchaud, A., Hansson, J., Affolter, M., Bel Rhlid, R., Piu, S., Moreillon, P., and Kussmann, M. (2008). ANIBAL, stable isotope-based quantitative proteomics by aniline and benzoic acid labeling of amino and carboxylic groups. Mol Cell Proteomics 7, 800-812.

Ross, A., Kessler, W., Krumme, D., Menge, U., Wissing, J., van den Heuvel, J., and Flohe, L. (2004a). Optimised fermentation strategy for 13C/15N recombinant protein labelling in Escherichia coli for NMRstructure analysis. J Biotechnol 108, 31-39.

Ross, P., Dey, S., Pillai, S., Daniels, S., Williamson, B., Guertin, S.., Minkoff, M., Chen, X., Purkayastha, B., Pappin, D (2006). Protein quantitation using a novel 8-plex set of isobaric peptide labels. 54th ASMS Conference, Seattle, WA ThP 62512.

Ross, P.L., Huang, Y.N., Marchese, J.N., Williamson, B., Parker, K., Hattan, S., Khainovski, N., Pillai, S., Dey, S., Daniels, S., et al. (2004b). Multiplexed protein quantitation in Saccharomyces cerevisiae using amine-reactive isobaric tagging reagents. Mol Cell Proteomics 3, 1154-1169.

Schaff, J.E., Mbeunkui, F., Blackburn, K., Bird, D.M., and Goshe, M.B. (2008). SILIP: a novel stable isotope labeling method for in planta quantitative proteomic analysis. Plant J 56, 840-854.

Schmidt, A., Kellermann, J., and Lottspeich, F. (2005). A novel strategy for quantitative proteomics using isotope-coded protein labels. Proteomics 5, 4-15.

Silva, J.C., Denny, R., Dorschel, C.A., Gorenstein, M., Kass, I.J., Li, G.Z., McKenna, T., Nold, M.J., Richardson, K., Young, P., et al. (2005). Quantitative proteomic analysis by accurate mass retention time pairs. Anal Chem 77, 2187-2200.

Thelen, J.J., and Peck, S.C. (2007). Quantitative proteomics in plants: choices in abundance. Plant Cell 19, 3339-3346.

Timms, J.F., and Cramer, R. (2008). Difference gel electrophoresis. Proteomics 8, 4886-4897.

Unlu, M., Morgan, M.E., and Minden, J.S. (1997). Difference gel electrophoresis: a single gel method for detecting changes in protein extracts. Electrophoresis 18, 2071-2077.

Wang, G., Wu, W.W., Zeng, W., Chou, C.L., and Shen, R.F. (2006). Label-free protein quantification using LC-coupled ion trap or FT mass spectrometry: Reproducibility, linearity, and application with complex proteomes. J Proteome Res 5, 1214-1223. 
Whitelegge, J.P., Katz, J.E., Pihakari, K.A., Hale, R., Aguilera, R., Gomez, S.M., Faull, K.F., Vavilin, D., and Vermaas, W. (2004). Subtle modification of isotope ratio proteomics; an integrated strategy for expression proteomics. Phytochemistry 65, 1507-1515.

Wu, C.C., MacCoss, M.J., Howell, K.E., Matthews, D.E., and Yates, J.R., 3rd (2004). Metabolic labeling of mammalian organisms with stable isotopes for quantitative proteomic analysis. Anal Chem 76, 4951-4959. Yao, X., Freas, A., Ramirez, J., Demirev, P.A., and Fenselau, C. (2001). Proteolytic 180 labeling for comparative proteomics: model studies with two serotypes of adenovirus. Anal Chem 73, 2836-2842. Yi, E.C., Li, X.J., Cooke, K., Lee, H., Raught, B., Page, A., Aneliunas, V., Hieter, P., Goodlett, D.R., and Aebersold, R. (2005). Increased quantitative proteome coverage with (13)C/(12)C-based, acid-cleavable isotope-coded affinity tag reagent and modified data acquisition scheme. Proteomics 5, 380-387.

Zhai, J., Liu, X., Huang, Z., and Zhu, H. (2009). RABA (reductive alkylation by acetone): a novel stable isotope labeling approach for quantitative proteomics. J Am Soc Mass Spectrom 20, 1366-1377.

Zhang, Y., Webhofer, C., Reckow, S., Filiou, M.D., Maccarrone, G., and Turck, C.W. (2009). A MS data search method for improved 15N-labeled protein identification. Proteomics 9, 4265-4270. 


\section{Figure captions}

Fig. 1. General HILEP workflow (A) for the relative quantitation of plant proteomes. (B) MS and MS/MS spectra of the ${ }^{14} \mathrm{~N}$ - and ${ }^{15} \mathrm{~N}$-labeled FEETLYGTSR peptide (monoisotopic mass of 1201.56 Da).

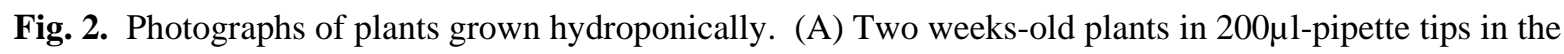
original pipette tip-box. Plants were grown on $0.7 \%$ agar and half-strength hydroponic medium. The last third of the tip has to be cut to allow root growth. (B) Plants transferred to lunch boxes containing fullstrength hydroponic medium. Five-weeks-old plants are shown. The medium is aerated with an aquarium pump. (C) \& (D) Seven-weeks-old healthy-looking plants grown in ${ }^{14} \mathrm{~N}$-hydroponic medium (C) and ${ }^{15} \mathrm{~N}$ hydroponic medium (D).

Fig. 3. Mass spectra of identified peptides from Arabidopsis plants grown hydroponically in ${ }^{14} \mathrm{~N}-$ or ${ }^{15} \mathrm{~N}-$ medium. Six-weeks-old plants were treated with $100 \mathrm{mM}$ hydrogen peroxide. Treated $\left({ }^{14} \mathrm{~N}\right)$ and control $\left({ }^{15} \mathrm{~N}\right)$ plants were pooled together when harvested $24 \mathrm{~h}$ later and leaf proteins were extracted from the apoplast (see experimental details in Bindschedler et al, 2008). Examples for different expression ratios are shown: (A) DTDILAAFR (Rubisco large SU; AtCg00490), monoisotopic mass of 1020.5 Da. (B) ALDENLLASPEK (probable endochitinase; At2g43570), monoisotopic mass of 1298.6 Da. (C) SGLVNEAAIDK (beta-xylosidase; At5g64570), monoisotopic mass of 1116.7 Da. 


\section{Index keywords}

HILEP

HYDROPONIC ISOTOPE LABELING OF ENTIRE PLANTS (HILEP)

HYDROPONICS

ISOTOPE LABELING

METABOLIC LABELING

PLANT PROTEOMICS

PROTEIN QUANTITATION

QUANTITATIVE PROTEOMICS

STABLE ISOTOPES

TRANS-PROTEOMIC PIPELINE (TPP) 


\section{HILEP - ㅂydroponic Isotope Labeling of Entire Plants}

A

${ }^{14} \mathbf{N}$
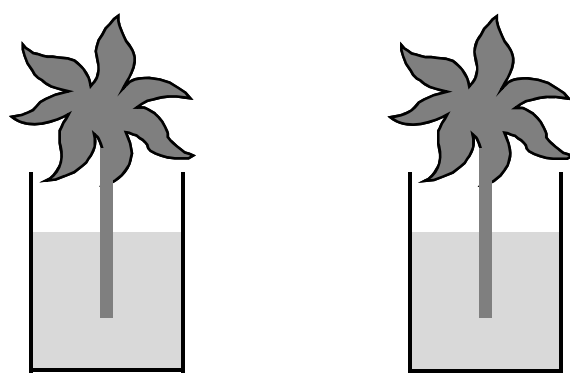

${ }^{15} \mathrm{~N}$

Protein extraction and fractionation

Proteolysis

LC-MS analysis and quantitation

B

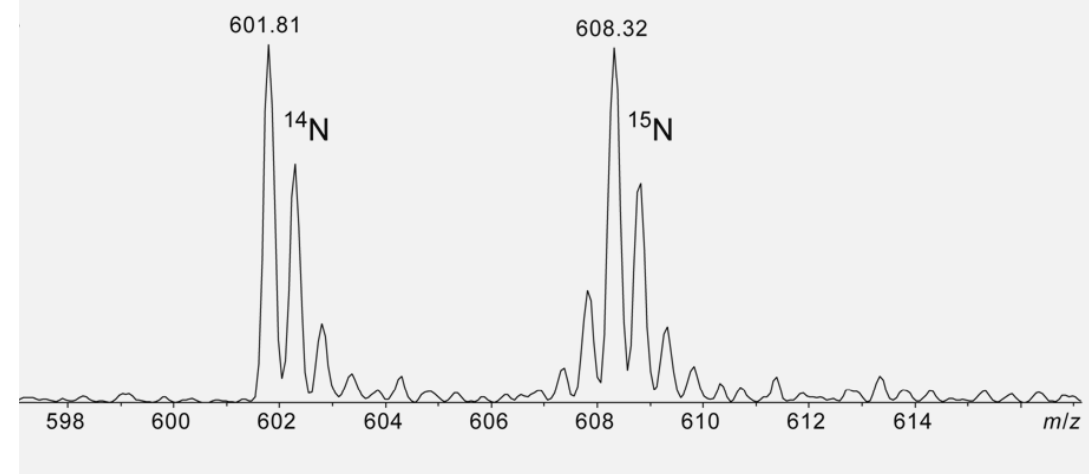

F E ETLYYGTS R

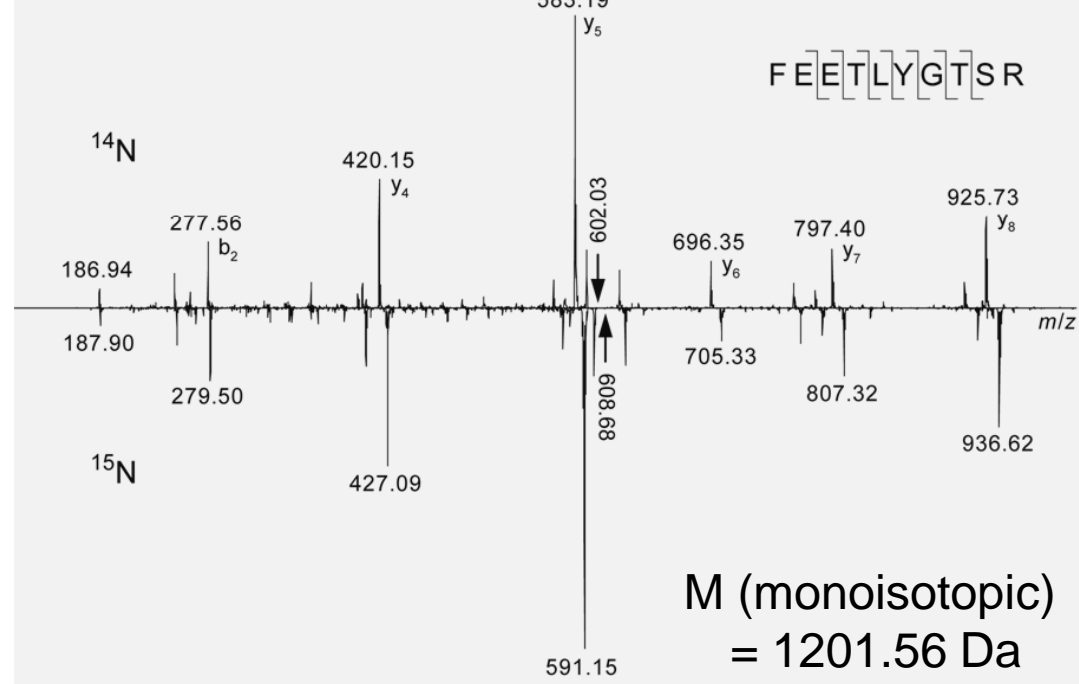

Fig. 1 




Fig. 2 

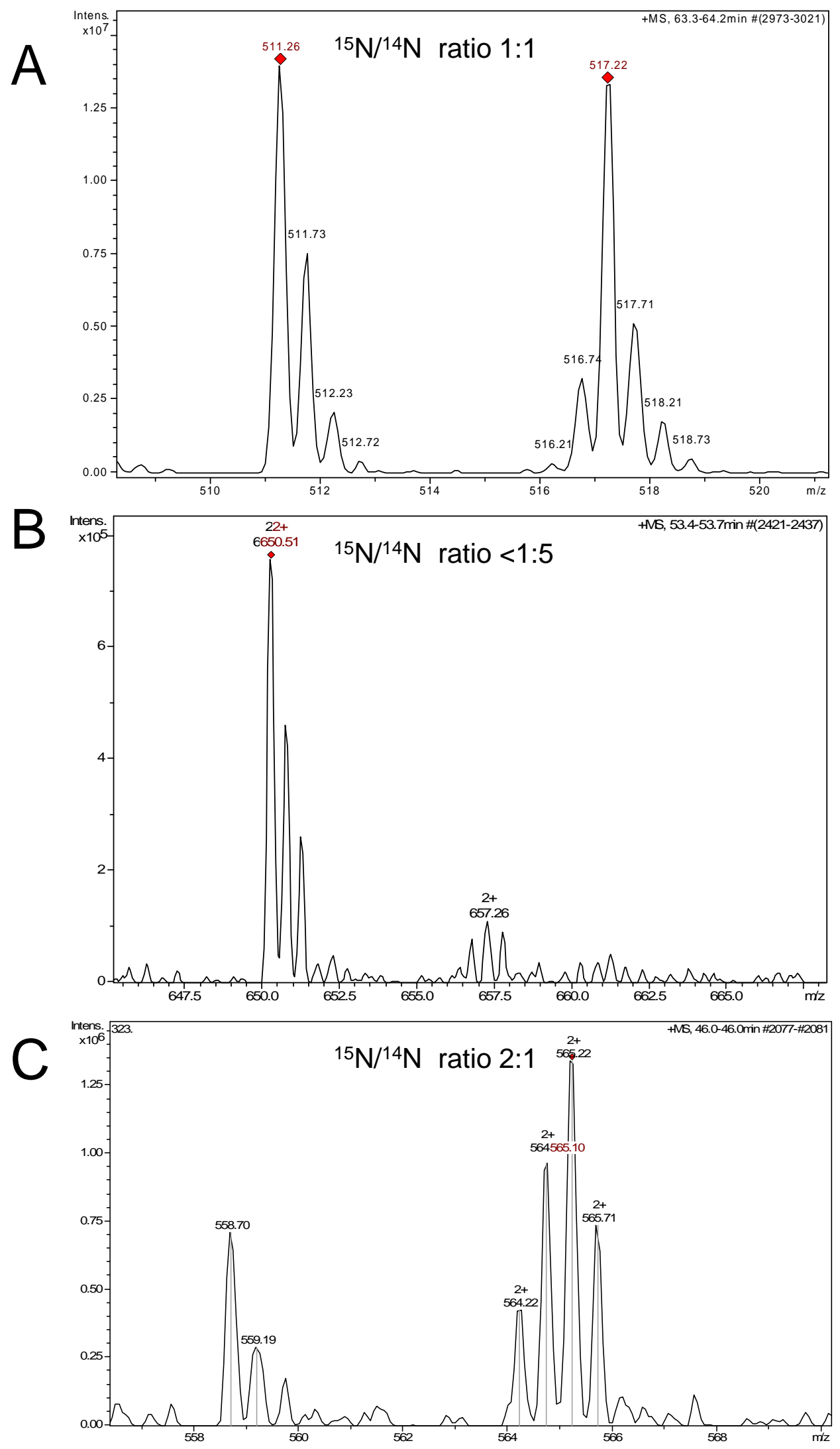

Fig. 3 